\title{
Evaluation of a mentorship program for new and more-experienced nursing faculty
}

\author{
Mélanie Lavoie-Tremblay, Christine Maheu, Daphné Octeau, Gilbert Primeau, Genevieve L. Lavigne \\ Ingram School of Nursing, McGill University, Canada
}

Received: January 10, 2019

Accepted: February 21, $2019 \quad$ Online Published: March 20, 2019

DOI: $10.5430 /$ jnep.v9n7p1

URL: https://doi.org/10.5430/jnep.v9n7p1

\begin{abstract}
Objective: Evaluation of a nursing faculty mentorship program available to every faculty member regardless of seniority. Methods: Design: The faculty mentorship program was developed and implemented in a university-affiliated nursing department in Montreal in 2018. Mentors and mentees evaluated the program using self-reported surveys one-year post-implementation. The surveys addressed three main themes: (a) determining goals of the mentoring partnership; (b) overall level of satisfaction with the program; and (c) characteristics of each dyad's mentoring agreement (strategies used to communicate, where the dyads met, etc.). Method: Quantitative and qualitative analyses were conducted.

Results: A total of 19 mentees and 15 mentors completed the survey. The program was judged to be a worthwhile use of time by $89 \%$ of mentees and $93 \%$ of mentors. Even though specific mentoring needs differed according to seniority level, the program was shown to be beneficial to both less-experienced and more-experienced faculty. The main barriers to mentorship that were identified were related to timing, scheduling and time commitment issues. Clinical relevance: A successful mentorship program aimed at fostering relationships between nursing faculty members, regardless of seniority, has the potential to improve the productivity of a healthy workplace including the quality of both teaching and research.

Conclusions: The mentorship program proposed herein was found to be useful and effective, as well as being beneficial as much for younger as for more experienced faculty members.
\end{abstract}

Key Words: Mentorship, Nursing faculty, Program evaluation

\section{INTRODUCTION}

The shortage in nursing academia continues to be a major issue that affects the capacity of nursing programs to educate and support the next generation of nurses. ${ }^{[1-3]}$ The implementation of mentoring programs has been identified as one of the ways to possibly prevent the high rates of premature departure of faculty members just entering the new role of academic leaders, as well as to reduce faculty turnover. ${ }^{[4-7]}$ Indeed, promoting teamwork and limiting isolation by bringing together new faculty members into the existing faculty group with a faculty mentorship program prevents frustration and work dissatisfaction, amongst other things. ${ }^{[4]}$
Although faculty mentorship programs in nursing primarily focus on the needs of new faculty members, the literature shows that more-experienced faculty also have mentoring needs. ${ }^{[6]}$ Isolation, stress, burnout and turnover are serious issues in nursing programs where mentoring is not offered, regardless of how experienced the faculty are. ${ }^{[8]}$ Some research has been conducted on peer mentoring (peer coaching) for experienced faculty members. In one study, ${ }^{[9]}$ mid-career and senior faculty participating in a peer coaching program noted that they learned a great deal from observing the teaching practices of colleagues with similar levels of experience to their own. The authors suggested that peer coaching pro-

\footnotetext{
* Correspondence: Mélanie Lavoie-Tremblay; Email: Melanie.lavoie-tremblay@ mcgill.ca; Address: Ingram School of Nursing, McGill University, Canada.
} 
grams are beneficial to more experienced faculty, as they allow for specific, contextualized, problem-based reflection on their teaching practices. Therefore, while most mentoring research are focused on junior faculty, midlevel and senior faculty members can also benefit from faculty mentorship programs. ${ }^{[5,6,10]}$ However, to our knowledge, there is no research focusing on the implementation and evaluation of a nursing faculty mentorship program that offers the opportunity to be a mentee at any level of career seniority. The School of Nursing Faculty Mentorship Program (FMP) was developed within the context of a University's Faculty of Medicine mentorship initiative (March 2017), which provided the impetus for the School of Nursing to develop its own faculty mentorship program. The FMP's aim was to implement a mentorship program beneficial to every nursing faculty member, not just the less-experienced ones, and to evaluate the specific needs of the mentees in relation to their level of seniority.

Some of the major limitations of the current literature on mentorship programs identified by Nowell et al. ${ }^{[6]}$ were the lack of description of mentorship programs' components and their evaluation post-implementation. The lack of overall evaluation of the overall effectiveness of mentorship programs was another major limitation of the current literature. Therefore, the purpose of this manuscript is to describe how the FMP has been developed, implemented and evaluated between 2017-2018, based on the nine main mentorship components identified by Nowell et al. ${ }^{[6]}$ (see Table 1). Those components are: (1) Having a program coordinator, (2) Orientation to the program, (3) Selectively matching dyads, (4) Clear purpose and goals, (5) Frequent communication, (6) Faculty development workshops, (7) Mentee reflective journaling, (8) Socialization and Networking, and (9) Administrative support. ${ }^{[6]}$ Regarding the fourth component, "clear purpose and goals", four program goals were identified by the FMP: (1) Increase the research productivity of the nursing faculty, (2) nurture and develop new nursing faculty, in order to foster retention and maximize faculty achieving tenure, (3) enhance collegiality and promote socialization within the faculty, and (4) when relevant, facilitate the transition from nurse clinician to nurse educator. To avoid any confusion in regards of the purpose and essence of the term mentorship, the definition used in this manuscript is the same as the one used by Nowell et al. (p335): ${ }^{[6] ~ " m e n t o r s h i p ~ i s ~ d e f i n e d ~ a s ~ a ~ d e v e l o p-~}$ mental, empowering, and nurturing relationship that extends over a period of time in which mutual sharing, learning, and growth occur in an atmosphere of respect, collegiality, and affirmation." (p4-5) ${ }^{[11]}$

Table 1. School of nursing faculty mentorship program key components of a mentorship program ${ }^{[6]}$

\begin{tabular}{|c|c|c|}
\hline $\begin{array}{l}\text { Components } \\
{\text { (adapted from Nowell et al. })^{[6]}}\end{array}$ & $\begin{array}{l}\text { Dates of } \\
\text { implementation }\end{array}$ & Implementation in the nursing mentorship Program \\
\hline Program Coordinator & March 2017 & $\begin{array}{l}\text { A program coordinator has been appointed at the beginning of the development of } \\
\text { the mentorship program. }\end{array}$ \\
\hline Administrative Support & June 2017 & $\begin{array}{l}\text { An advisory comity of } 6 \text { faculty members has been appointed to support and give } \\
\text { advises to the program coordinator throughout the duration of the program. }\end{array}$ \\
\hline Selectively Matching Dyad & May 2017 & $\begin{array}{l}\text { A Faculty wide survey have been done to match the Dyads based on shared areas } \\
\text { of interest, perceived mentorship needs and personal preference to facilitate } \\
\text { building a reciprocal relationship. A total of } 24 \text { dyads were established, later } \\
\text { increasing to } 25 \text { in Spring } 2018 \text {. }\end{array}$ \\
\hline Orientation to the program & September 2017 & An orientation session to the program has been provided by a faculty member. \\
\hline Developing clear purpose and goals & & $\begin{array}{l}\text { The } 4 \text { objectives of the program were based on those commonly identified by } \\
\text { Nowell et al. }{ }^{[6]} \text { : } \\
\text {-Increase research productivity of nursing faculty } \\
\text {-Nurture and develop new nursing faculty, foster retention, and maximize } \\
\text { faculty achieving tenure } \\
\text {-Enhance collegiality and promote socialization within the faculty } \\
\text {-Facilitate the transition from nurse clinician to nurse educator } \\
\text { The mentor/mentee have been encouraged to fill the Mentorship Agreement in } \\
\text { order to delineate the structure and purpose of the mentor/mentee relationship. } \\
\text {-Ground rules for communication } \\
\text {-How often and where meetings will take place } \\
\text {-Goals and objectives of the mentoring experience } \\
\text {-A timeline or way of measuring if the objectives have been met } \\
\text {-Expectations of mentors and mentees }\end{array}$ \\
\hline \multirow{2}{*}{$\begin{array}{l}\text { Frequent communication between } \\
\text { mentors and mentee }\end{array}$} & March 2017 & $\begin{array}{l}\text { In a Faculty-wide survey, the mentor/mentee have plurally responded they } \\
\text { preferred to have meetings every } 2 \text { months. }\end{array}$ \\
\hline & June 2017 & $\begin{array}{l}\text { The Mentoring Agreement document was also there to allows the mentors and } \\
\text { mentees to come up with efficient ways to communicate (E-mail, meetings, etc.) } \\
\text { and frequency of follow-up. }\end{array}$ \\
\hline
\end{tabular}




\section{MethodS}

\subsection{Design}

A descriptive, cross-sectional design was used to describe how the FMP has been developed, implemented and evaluated between 2017 and 2018 .

\subsection{Developmental phase}

School of Nursing Faculty Mentorship Program (FMP), university-affiliated, Quebec (Canada). Starting in March 2017, the Faculty of Medicine (FOM) launched a FOM-wide mentorship initiative under the leadership of the Assistant Dean of Faculty Affairs. This initiative provided the school of nursing with an opportunity to work together with the FOM in order to develop a school-based mentorship program aligned with the FOM initiative. At the time the initiative began, there was no formal mentorship program at the school of nursing, but one was needed to assist with the increased number of new faculty within the school. This was also in keeping with the strategic plan for 2016-2020, which has as one of its objectives, to develop a nursing mentorship program for new and current faculty, in addition to providing opportunities to increase faculty communication with professional and research networks. The FMP was based around a formal 1:1 mentorship relationship.

In May 2017, a survey was sent to all faculty from the School of Nursing asking if they would like to be a named mentor or mentee or both in the FMP. A total of 30 faculty members completed the survey. Dyads were matched based on shared areas of interest, perceived mentorship needs, and personal preferences. In cases where there was a pre-existing, informal mentorship dyad within the School of Nursing, and both parties wanted the dyad to continue, they were offered to have their partnership formally recognize by completing proper documentation but no changes were made to their arrangement. For faculty without a pre-existing mentorship dyad that they wished to continue within the framework of the FMP, dyads were proposed based on who mentees had chosen as their preferred mentors on the survey, as well as their best match based on needs and strengths. For mentees whose preferred mentor(s) were unavailable, they were sent a list of remaining available mentors, as well as their best match based on needs and strengths, and were asked for two suggestions for potential mentors. For mentees who did not indicate a preferred mentor on the survey, they were sent a list of available mentors, their best match based on needs and strengths, and asked for two suggestions for dyads.

\subsection{Implementation phase}

Once the mentees had made their selections, both parties were emailed separately and asked if they agreed to the pro- posed dyad. If the mentee declined, they were asked for three new suggestions from the list of remaining available mentors. If the mentor declined, they were provided with suggestions for other potential mentees. Using this process, 25 mentor/mentee dyads were established. In this program, one mentor is able to have several mentees. Once the dyads were established, the program coordinator emailed all FMP participants with a copy of the project overview and the mentoring agreement. Participants were also invited to an optional program orientation session held in September 2017 and were notified that the program would be evaluated in May 2018. For mentors participating in the program, three breakfast seminars were held in January, March and April of 2018. The goal of the breakfast seminars was to provide mentors with a space to share their experiences with one another and to provide each other with feedback and support. In June 2018, mentees and mentors were all sent a survey to evaluate the FMP. The present research reports on the results of this survey.

\subsection{Evaluation phase}

Mentees' and mentors' surveys were composed of several descriptive questions (17 questions for mentees and 26 for mentors) regarding their involvement in the FMP and their perceptions about the program. The surveys included several short-answers questions where mentees and mentors could expand on their thoughts regarding different aspects of the program. Sample questions included "What are the primary goals of your mentoring relationship?", "Do you feel that the mentorship program is an effective use of your time?' and "What are the benefits (if any) of the faculty mentorship program?" Mentors' and mentees' socio-demographic information was also collected. This survey was revised and approved by the nursing mentorship advisory committee made up of nine faculty members. Mentees also completed Berk et al.'s ${ }^{[12]}$ Mentorship Effectiveness Scale. This scale was developed in order to provide a standardized comprehensive measures of mentorship effectiveness. The scale is composed of 12 items answered on a 6-point Likert-type scale ranging from "Strongly disagree" to "Strongly agree". A total score is computed by summing all 12 items, thus scores can vary from 12 to 60 with higher score indicating higher effectiveness of the mentoring relationship. Berk and colleagues ${ }^{[12]}$ provided some evidence for the validity and reliability of the scale.

\subsection{Data analysis}

Means, standard-deviations and frequencies were computed for all quantitative questions. For open questions, qualitative data were analyzed using a method of thematic content analysis developed by Miles and Huberman. ${ }^{[13]}$ 


\subsection{Ethical considerations}

Ethical approval for the study was obtained from the Institutional Review Board of the McGill University Faculty of Medicine (A09-E65-17A). On the introductory page for the survey, participants were informed that by submitting their survey responses (through LimeSurvey), participants indicated their consent to participate in this study.

\section{RESULTS}

A total of 19 mentees (response rate of 79.17\%) and 15 mentors (response rate of $71.43 \%$ ) completed the survey. However, one mentee reported never meeting with their mentor and was thus excluded from most analyses. About $65 \%$ of the mentees and 58\% of mentors were aged between 35 and 54 years old. Mentees had been at the School of Nursing for an average of 7.22 years ( $\mathrm{SD}=5.91$ ) while mentors had been at the School of Nursing for an average of 9.23 years $(\mathrm{SD}=6.61)$. The majority of mentees $(72 \%)$ and mentors (83\%) were contract academic staff (appointments that do not lead to tenure).

\subsection{Mentees}

Mentees reported an average of 4.94 meetings with their mentor within this one year, most of which (78\%) occurred at the School of Nursing. Mentees most frequently reported emails (94\%) and hallway exchanges (67\%) as the type of communications between themselves and their mentor. A little more than half of the mentees (56\%) completed the mentorship agreement but of those who did, $90 \%$ found the agreement useful. Some of the goals reported by mentees for the mentoring relationship were conflict management, leadership development, dealing with department politics, teaching and program development as well as sharing knowledge and resources about teaching, publication, and research. When comparing the mentoring relationship goals of the mentees with five or less years of experience within the School of Nursing to those of the mentees with more than five years of experience (see Table 2), it was noticed that mentees with less experience were seeking guidance on teaching, career planning, developing leadership and programs and hoped to be able to share knowledge and resources with their mentor. Mentees with more than five years of experience also hoped to get guidance on teaching and career planning but they were more likely to want to be mentored about research and publications. Mentees' scores on the effectiveness of faculty mentoring relationship measures indicated a high level of agreement with the measure's items, with a total score of $53.26(\mathrm{SD}=5.65)$ (see Table 3). The highest scores were found on the following items "My mentor was approachable", "My mentor was supportive and encouraging", "My mentor demonstrated professional integrity", and "My mentor demonstrated content expertise in my area of need."

Table 2. List of primary goals for the mentoring relationship based on years of experience within the School of Nursing

\begin{tabular}{|c|c|}
\hline 5 or less years of experience within the School of Nursing & 6 or more years of experience within the School of Nursing \\
\hline $\begin{array}{l}\text { Leadership development } \\
\text { Guidance in program development } \\
\text { Sharing knowledge and resources } \\
\text { Balancing roles }\end{array}$ & $\begin{array}{l}\text { Learning to delegate } \\
\text { Publication } \\
\text { Research } \\
\text { Integration within the School of Nursing } \\
\text { Navigating the politics }\end{array}$ \\
\hline \multicolumn{2}{|c|}{ Similar Goals } \\
\hline $\begin{array}{l}\text { Work/Life Balance } \cdot \text { Conflict Management } \bullet \text { Career Planning } \\
\text {-Teaching }\end{array}$ & $\begin{array}{l}\text { Work/Life Balance } \cdot \text { Conflict Management } \cdot \text { Career Planning } \\
\cdot \text { Teaching }\end{array}$ \\
\hline
\end{tabular}

\subsection{Mentors}

Mentors reported an average of 3.93 meetings with their mentee during that year, with a little more than half $(60 \%)$ occurring at the School of Nursing. The most frequently used method of communication was email (87\%) followed by hallway exchanges $(60 \%)$ and occasional office drop-ins (53\%). About half of the mentors (53\%) completed the mentoring agreement, and $88 \%$ of those who did found the agreement useful. In terms of preparation for being a mentor, $87 \%$ reported feeling adequately prepared, $40 \%$ mentioned they would need additional training, and $47 \%$ believed mentees needed more training as well. Regarding the mentors' break- fast seminars, $67 \%$ reported participating, $100 \%$ of those who did report, found the seminar at least somewhat useful.

\subsection{Satisfaction with the program}

The FMP was judged a useful expenditure of time by $89 \%$ of the mentees and $93 \%$ of the mentors. Similarly, $79 \%$ of mentees and $87 \%$ of mentors were either satisfied or very satisfied with the overall mentorship program. Table 4 presents the verbatim of the mentees and mentors rating of the program. Overall, mentees appreciated having someone to offer them guidance and to have someone they could talk to. Some mentees mentioned that even if they only met with their 
mentor a few times, they felt the mentorship was beneficial. of them described the relationship as a mutually beneficial Some of them highlighted that time constraints were a barrier collaboration. Mentors also reported that time constraints to developing a mentor/mentee relationship. Mentors apprewere a barrier to the program. ciated the opportunity to help a colleague, and a number

Table 3. Mentee's average score of effectiveness of faculty mentoring relationship; per item and total score (range 0-5)

\begin{tabular}{ll}
\hline & Mean (SD) \\
\hline My mentor was accessible & $4.47(.61)$ \\
My mentor demonstrated professional integrity & $4.74(.45)$ \\
My mentor demonstrated content expertise in my area of need & $4.68(.48)$ \\
My mentor was approachable & $4.84(.37)$ \\
My mentor was supportive and encouraging & $4.79(.54)$ \\
My mentor provided constructive and useful critiques of my work & $4.32(.82)$ \\
My mentor motivated me to improve my work product & $4.26(.73)$ \\
My mentor was helpful in providing direction and guidance on professional issues & $4.47(.77)$ \\
My mentor answered my questions satisfactorily & $4.47(.51)$ \\
My mentor acknowledged my contributions appropriately & $4.00(.88)$ \\
My mentor suggested appropriate resources & $4.16(.90)$ \\
My mentor challenged me to extend my abilities & $4.05(.85)$ \\
Total score & $53.26(5.65)$ \\
\hline
\end{tabular}

Some mentees and mentors offered suggestions to improve the FMP. These included more follow-ups or reminders to the mentee/mentor dyad to facilitate involvement in the program and offering workshops to mentors on topics such as conflict management, how to give feedback and how to promote engagement in the mentee/mentor relationship. One mentor also suggested to make the completion of the mentorship agreement mandatory to the program.

\section{Discussion}

Mentoring programs designed for faculty members have been suggested as one way to reduce the high rate of turnover in academic settings, ${ }^{[6]}$ which has become a challenging issue in nursing academia. In line with a recent literature review $^{[6]}$ that identified the major limitations of previous mentorship programs, the FMP was developed, implemented and evaluated based on the nine main mentorship components presented in the background section of this paper. ${ }^{[6]}$ A total of 25 dyads were created (see Table 1). The present research reports on the one-year evaluation of the program as much from the mentees' as from the mentors' point of view. Overall, satisfaction with the program was very high, and it was judged a useful expenditure of time by most participants. Mentees rated the effectiveness of their mentoring relationships with a standardized tool, ${ }^{[12]}$ and the overall score was very high (average of 53.26 on a scale ranging from 12 to 60 , see Table 3). The highest scored items were "My mentor was approachable", "My mentor was supportive and encourag-

Published by Sciedu Press ing", and "My mentor demonstrated professional integrity". Thus, we are confident that overall the FMP was effective and useful in fostering mentoring relationships between nursing faculty members.

While most mentorship research focuses on the needs of new faculty members, such as in senior-junior dyads, more experienced and senior faculty members could also benefit from a mentoring relationship. ${ }^{[6,8]}$ As we have observed from our program, mid-career mentee benefited from the mentorship of senior faculty either research guidance or teaching. Huston and Weaver ${ }^{[9]}$ who developed a peer mentoring program with a focus on teaching, highlighted the benefits of a mentoring relationship for mid-career and senior faculty members. They further highlighted that the specific needs of more experienced faculty are not generally met in standard academic workshops, and thus a mentoring relationship with a talented colleague is highly beneficial to them. Similarly, other authors have also highlighted that mid-career and senior faculty members have career needs that are different than those of younger faculty members. ${ }^{[14]}$

As the literature documented this need for all faculty, regardless of seniority, to receive peer-mentoring it was for this reason that the FMP was designed to make the mentoring relationship available to all faculty members, including more experienced ones. Table 2 presents the different goals for the mentoring relationship as described by mentees with five or less years of experience within the School of Nursing. 
Table 4. Mentees' and Mentors' reasoning for rating the faculty mentorship program as they did

\begin{tabular}{l} 
Mentees \\
\hline Scheduling. Time commitment, Timing \\
"Scheduling times were at times difficult, but we managed to meet." \\
"I appreciate the initiative, but my teaching load is challenging and \\
unfortunately accomplishing this takes priority above organizing \\
individual sessions during the intense semester. I prefer to use a \\
more informal as needed approach with a number of colleagues that I \\
identify with as supportive coaches (there are many).” \\
“At this point it is hard to say that I am satisfied as it was difficult to \\
find time to meet with my mentor. We are both extremely busy and \\
are at two different sites. The motivation and interest is absolutely \\
present but feasibility makes it challenging. I will have to review \\
this with my mentor to find out her impression. Would like to \\
continue this relationship.” \\
"I think the mentorship program is a great idea. However, I didn't \\
formalize my relationship with my mentor so I can't say that it was \\
not effective - I just never invested the time to get more engaged in \\
the process. On the other hand, my friend/colleague is always willing \\
to provide advice when I have questions.” \\
“Timing was appropriate for the mentoring that was needed. I had \\
started in new courses and my mentor was familiar with the learning \\
context and the students.”
\end{tabular}

\section{Positive Impacts: well being, self confidence, useful}

"My relationship and work with my mentor has had a positive impact on my well-being as well as being a catalyst for self-improvement.”

“Because I'm satisfied.”

"Great opportunity to discuss with others."

"I only had to meet my mentor once, but it was a really useful meeting."

"It has been very useful to be able to draw from someone else experience.”

"My mentor has helped support me and given me the confidence to achieve something I thought was not possible, she has full confidence in my abilities and has brought innovative new ideas to the surface that are helping me with the pedagogy, and the management of my courses, as well as my functioning at the school. She brings to the table what friends or colleagues cannot.”

"It is great to be able to talk to some with more experience in navigating the politics of the dept."

"Very useful."

"It was a wonderful opportunity to check in and verify and validate experiences.”

"Very useful to have someone you can rely on even if you do not meet often."

"It was helpful, mainly at the start of the transition to this new role."

Safe Space

"It was nice to feel I had a safe space to work on issues that my mentor brought a different perspective and experience. They motivated me to address the issues that were challenging to me."

\section{Mentors}

Scheduling. Time commitment, Timing

“The program is great. We have busy schedule, I wish I had more time for it.”

"Program would be better if I personally could invest more time.”

"I am not sure if my mentee felt it was useful to them. They did not ask to meet very much."

"As a senior faculty member, I have mentored in past and feel comfortable doing so without support, so do not need training. My relationship with the mentee existed prior to the program. I could not count the number of times we met or interacted - frequent informal contacts occurred in many forms."

"My mentee didn't seem to want to meet again. We only met once despite repeated attempts to reach out on my part.”

\section{Connection}

"It is very good to have this kind of connexion with colleagues, trusting and helpful”

"It is a great opportunity to know someone and contribute to his thinking and learning"

\section{Mutual Benefit}

"It was a win-win on all levels and an opportunity to pay it forward"

"Relationship is genuine and of mutual benefit to mentee and mentor”

"I really enjoyed working with my colleague. Did not feel very 'mentor/mentee'. Much more a collaborative venture.”

Other

“Great support”

"This is an important concept that is difficult to put into practice however with the expected turnover in both academic and clinical leaders in the next ten years finding ways to support incoming and mid-career staff to achieve expected goals is necessary, this program can potentially strengthen the university's nursing network, which will be so necessary as the health care system evolves.”

"Unfortunately, my first experience as mentor in this program was not as productive as I had imagined. I have been a mentor before in other contexts and these collaborations were very successful. I think there needs to be greater accountability built into this program. Considerable resources have been invested; it would be important to see positive outcomes.” 
Although some goals such as teaching, career planning, conflict management and work-life balance were reported by both groups of mentees, our results highlight different needs as well. Specifically, junior faculty members sought guidance on program development, on how to develop their leadership skills, and on balancing roles, and hoped to share some knowledge and resources with their mentor, while more experienced faculty members were seeking mentorship on research and academic publication, on how to delegate, and on how to integrate and navigate the politics within the School of Nursing. Our results thus emphasize the importance of developing mentorship programs available to all levels of seniority, as these relationships are beneficial and enriching at all career-levels.

When asked about their thoughts on the mentorship program, participants identified several challenges. Timing, scheduling, and time commitment were identified as the main barriers by both mentors and mentees. Despite this reality, mentees reported finding the mentoring relationship very useful and satisfying, and several mentees reported a positive impact on their confidence level due to this opportunity to share different perspectives, as well as to have a safe space to discus and validate experiences. Mentors appreciated the opportunity to form a connection with a colleague and to play a part in their professional development. Mentors also reported that the mentoring relationship was mutually beneficial, which is in line with Huston \& Weaver's ${ }^{[9]}$ peer coaching participants, who reported learning a lot from each other. Interestingly, the participants in Huston and Weaver's study ${ }^{[9]}$ were experienced university professors from diverse departments, once again suggesting that faculty mentoring programs should be offered to all faculty members regardless of seniority level and perhaps departmental origin.

One interesting strategy suggested by Lasater et al. ${ }^{[15]}$ that could help support more-experienced faculty members as well as alleviate timing and scheduling barriers could be online mentoring. The mentee-mentor dyads could be matched not only within one school of nursing but also between different institutions, which could result in more mid-career and senior faculty members finding a high-quality mentorship match, which as a significant impact on the quality of the mentorship relationship itself. ${ }^{[6]}$ Future research investigating this strategy would be beneficial.

\section{Limitations}

The present research has some limitations. First, the mentoring program presented was only implemented in one school of nursing. Second, due to the limited size of the school of nursing, only 25 mentee-mentor dyads were created, and although the one-year response rate was high, not all participants evaluated the program. Future research should seek to determine if a mentoring relationship such as the one proposed in the present research could positively impact mentees' performance as researchers as well as ultimately reduce turnover.

\section{Conclusion}

The FMP presented in the present research was developed, implemented and evaluated while being mindful of the limitations commonly found in mentorship programs as identified in a recent literature review. ${ }^{[6]}$ Mentee-mentor dyads were formed within the school of nursing, and the results following the program's evaluation suggest that the program was useful and effective. Most importantly, the program was found to be equally beneficial for both less- and more-experienced faculty members.

\section{FUNDING SOURCE}

This work was supported by the McGill Nursing Collaborative for Education and Innovation in Patient and Family Centered Care (Newton Foundation/McGill Faculty of Medicine). Daphné Octeau received a Summer Bursary from the ISoN for this work.

\section{ACKNOWLEDGEMENTS}

The authors would like to acknowledge the contribution of Dr Lesley Fellows, Lia Sanzone and Molywan Vat in the development of this mentorship program as well as the school of nursing mentorship faculty advisory committee (Rosetta Antonacci, Susan Drouin, Francoise Fillion, Melanie Gauthier, Sylvie Lambert, Caroline Marchionni, Lia Sanzone). The authors acknowledge support from The McGill Nursing Collaborative for Education and Innovation in Patient and Family-Centred Care (Newton Foundation/McGill Faculty of Medicine) and Graphos/McGill Writing Centre through the Writing for Publication initiative.

\section{CONFlicts of InTEREST Disclosure}

The authors declare that there is no conflict of interest.

\section{REFERENCES}

[1] American Association of Colleges of Nursing. Nursing Faculty Shortage Fact Sheet. 2012. Available from: http://www . aacnnursing. org/Portals/42/News/Fact
sheets/Faculty-Shortage-Factsheet-2017.pdf

[2] Canadian Association of Schools of Nursing. Registered Nurses Education in Canada Statistics. 2016. Available from: http://www. casn.ca/wp-content/uploads/2016/11/201 
4-2015-SFS-FINAL-REPORT-suppressed-updated.pdf

[3] Vandyk A, Chartrand J, Beké É, et al. Perspectives from Academic Leaders of the Nursing Faculty Shortage in Canada. International Journal of Nursing Education Scholarship. 2017; 14(1).

[4] Dunham-Taylor J, Lynn CW, Moore P, et al. What Goes Around Comes Around: Improving Faculty Retention Through More Effective Mentoring. Journal of Professional Nursing. 2008; 24(6): 337346. PMid:19022206 https://doi.org/10.1016/j.profnurs .2007 .10 .013

[5] Law AV, Bottenberg MM, Brozick AH, et al. A Checklist for the Development of Faculty Mentorship Programs. American Journal of Pharmaceutical Education. 2014; 78(5): 98. PMid:24954938 https://doi.org/10.5688/ajpe78598

[6] Nowell L, Norris JM, Mrklas K, et al. A literature review of mentorship programs in academic nursing. Journal of Professional Nursing. 2017; 33(5): 334-344. PMid:28931480 https://doi.org/10.1 016/j.profnurs. 2017.02.007

[7] Vogelsang LE. Early Succession Planning for Nursing Faculty. Nurse Education Today. 2014; 34(10): 1277-1279. PMid:24969416 https://doi.org/10.1016/j.nedt. 2014.05.015

[8] Chung CE, Kowalski S. Job Stress, Mentoring, Psychological Empowerment, and Job Satisfaction Among Nursing Faculty. Journal of Nursing Education. 2012; 51(7): 381-388. PMid:22588567 https://doi.org/10.3928/01484834-20120509-03
[9] Huston T, Weaver CL. Peer coaching: Professional development for experienced faculty. Innovative Higher Education. 2008; 33(1): 5-20. https://doi.org/10.1007/s10755-007-9061-9

[10] Rockquemore KA. Mid-career mentoring. 2011. Available from: http://www . insidehighered.com/advice/2011/11/28/e ssay-need-tenured-faculty-members-havementoring

[11] Vance C, Olson R. The mentor connection in nursing. New York: Springer Pub; 1998.

[12] Berk RA, Berg J, Mortimer R, et al. Measuring the effectiveness of faculty mentoring relationships. Academic Medicine. 2005; 80(1): 66-71. PMid:15618097 https://doi.org/10.1097/00001888 $-200501000-00017$

[13] Miles MB, Huberman AM. Qualitative data analysis: An expanded sourcebook. Thousand Oaks: Sage Publications; 1994.

[14] Seldin P. Tailoring faculty development programs to faculty career stages. In S. Chadwick-Blossey \& D. R. Robertson (Eds.), To improve the academy: Resources for faculty, instructional and organizational development. Bolton, MA: Anker. 2006.

[15] Lasater K, Young PK, Mitchell CG, et al. Connecting in distance mentoring: Communication practices that work. Nurse Education Today. 2014; 34(4): 501-506. PMid:23978777 https : //doi .org/ 10.1016/j.nedt. 2013.07.009 